\title{
Digitization of Structured Composite Plates with Regard to Their Numerical Simulations
}

Petr Kulhavý, Petr Lepsik

Faculty of Mechanical Engineering, Technical University of Liberec, Studentská 2, 461 17, Liberec 1, Czech Repulic. E-mail: petr.kulhavy@tul.cz,petr.lepsik@tul.cz

A method of 3D scanning and a subsequent data reconstruction presented in this paper are focused on digitization of highly structured composite parts with regard to creation of a fully functional CAD and FEM model. The digitized parts are structured carbon composites made replication of steel templates. Production of steel templates is a technological procedure mostly based on pressing or rolling. However, the data obtained from 3D scanner are not in appropriate format, there are a cloud of points interleaved by a sufrace and it is necessary to use some aditional methods to solidify the resulting geometry. Most often with using commercial software as for example: Creo, Catia, Inventor, Rhino or Geomagic studio is the cloud of points parameterized in a continuous surface. Now, based on some next operations (intersections, blends) the desired solidified model in CAD format could be achieved. Despite the relatively rapid creation of the main shape the minor inaccuracies that occur during noncontact measurement results either in local areas or individual points with a large deflection. The aim of this thesis was to assess the appropriate method for creating geometry and compensation the inaccuracies with regards to numerical simulations, especially the meshing and convergency of a solved model. As has been quite surprisingly found, some local small step changes in the geometry could be for the calculation easier to solve than a complicated and highly approximated area. An influence to a solution does not seem important.

Keywords: Composite plates, 3D scan, Reverse engineering, Free surfaces, Mesh

\section{Acknowledgements}

This publication was written at the Technical University of Liberec as part of the project "Innovation of technical systems structures with the use of composite materials" with the support of the Specific University Research Grant, as provided by the Ministry of Education, Youth and Sports of the Czech Republic in the year 2016.

\section{References}

[1] KRAHL T., Untersuchung der mechanischen Eigenschaften an strukturierten Feinblechen, (2014). Masterthesis, HS-Lausitz.

[2] SIMON S., Werkstoffgerechtes Konstruieren und Gestalten mit metallischen Werkstoffen, (2005). Habilitation thesis, Brandenburgischen Technischen Universität Cottbus.

[3] THILL C., ETCHES J.A., BOND I.P. (2010). Investigation of trapezoidal corrugated epoxy laminates under large tensile displacements transverse to the corrugation direction, (2010). Applied Science and Manufacturing, 41.

[4] BRIASSOULIS D. (1986). Equivalent orthotropic properties of corrugated sheets, (1986). Computers \& Structures Vol. 23, Issue 2.

[5] SAMANTA, A., M. MUKHOPADHYAY, Finite element static and dynamic analysis of folded plates, (1999). Engineering Structures, 21.

[6] NOVAK-MARCINCIN, J., et.al., (2012). Technology of Perspective Scanning Methods for Realization of 3D Models of Manufacturing Devices, Manufacturing Technology, 186-191.

[7] DRBÚL, M., et.al., (2016). Simulation Possibilities of 3D Measuring in Progressive Control of Production, $M a-$ nufacturing Technology, p. 53-58.

[8] KULHAVY, P., PETRU, M., SRB, P. (2014). Numerical and experimental analysis the pressure looses of the heat convector. In: Strojirenská technologie: Vol. 3, Issue 4.

[9] KUlHAVY, P., KOVAlOVA, N., VOSAHLO, J. (2015). Numerical Model of the Static Loading of a Stitched Seam in the Composite Cover of Car Seat, Applied Mechanics and Materials: Vol. 827, Trans tech publication.

[10] KULHAVY, P., SRB, P., PETRU, M. (2015). Numerical and experimental analysis of the real load arising in the cushion of the car seat, Manufacturing technology, Vol. 15, Issue 6.

[11] PATEK, M. et.al. (2016). Numerical Analysis of T-Joint Welding with Different Welding Sequences, (2016). Manufacturing Technology, p. 234-238.

[12] Practical Aspects of Finite Element Simulation, (2015). Altair Engineering, United States.

[13] Mechanical Structural Nonlinearities - Meshing in mechanical, (2010). Training Material, ANSYS, Inc. Proprietary. 